Medical Scope Journal (MSJ). 2019;1(1):21-25

Available from: https://ejournal.unsrat.ac.id/index.php/msj

\title{
Hubungan antara Beban Kerja Fisik dengan Kelelahan Kerja pada Pekerja Industri Pembuatan Mebel Kayu di Desa Leilem Satu
}

\author{
Giani C. Reppi, Lery F. Suoth, Grace D. Kandou
}

Fakultas Kesehatan Masyarakat Universitas Sam Ratulangi Manado

Email: gianiclaudia34@gmail.com

\begin{abstract}
Work fatigue is a condition of decreased working performance of an individual. Workload could cause work fatigue, therefore, work burden -physically and mentally- has to be individually adjusted. This study was aimed to evaluate the relationship between work fatigue and workload among workers of furniture manufactures at Desa Leilem Satu. This was an observational analytical study with a cross sectional design. Population consisted of all workers of furniture manufactures at Leilem Satu village with a total number of 72 workers. There were 42 respondents involved in this study. Data were analyzed by using the Spearman Rank correlation test. The Spearman Rank correlation test of the relationship between work fatigue and workload obtained a p-value of $0.039(<0.05)$. In conclusion, there was a significant relationship between work fatique and workload among workers of furniture manufactures at Desa Leilem Satu.
\end{abstract}

Keywords: workload, work fatigue

\begin{abstract}
Abstrak: Kelelahan kerja merupakan suatu keadaan dimana terjadi penurunan performa kerja dari seseorang. Beban kerja merupakan salah satu faktor penunjang terjadinya kelelahan kerja sehingga beban kerja yang diterima baik beban kerja fisik maupun mental harus sesuai dengan kemampuan fisik dan mental pekerja. Penelitian ini bertujuan untuk mengetahui hubungan antara beban kerja fisik dengan kelelahan kerja pada pekerja industri pembuatan mebel kayu di Desa Leilem Satu. Jenis penelitian ialah analitik observasional dengan desain potong lintang. Populasi yang digunakan yaitu seluruh pekerja di industri pembuatan mebel kayu di Desa Leilem Satu berjumlah 72 orang. Jumlah sampel yang didapatkan yaitu 42 orang. Data penelitian diuji dengan menggunakan uji korelasi Spearman Rank. Hasil uji Spearman Rank terhadap hubungan antara beban kerja fisik dengan kelelahan kerja mendapatkan nilai $\mathrm{p}=0,039$ $(<0,05)$. Simpulan penelitian ini ialah terdapat hubungan bermakna antara beban kerja fisik dengan kelelahan kerja pada pekerja industri pembuatan mebel kayu di Desa Leilem Satu.
\end{abstract}

Kata kunci: beban kerja, kelelahan kerja

\section{PENDAHULUAN}

Keselamatan dan kesehatan kerja merupakan salah satu bidang ilmu yang berupaya agar supaya para pekerja dalam keadaan sehat, selamat dan bahkan sejahtera, dan juga berfungsi untuk melindungi agar semua sumber produksi dapat digunakan secara efektif. Dewasa ini berdasarkan data Badan Pusat Statistik Tahun 2018, di Indonesia terdapat 127,07 juta jiwa bekerja di sektor formal maupun informal dan 6,87

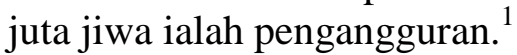

Kelelahan kerja merupakan suatu keadaan dimana terjadi penurunan perfor-ma kerja seseorang. Dalam Undang-Undang No. 13 Tahun 2003 tentang Ketenagakerjaan, sangat jelas dinyatakan bahwa setiap pekerja berhak untuk mendapatkan perlindungan atas keselamatan dan kesehatan kerja, moral dan kesusilaan serta perlakuan yang sesuai dengan harkat dan martabat manusia serta nilai-nilai agama. ${ }^{2}$ Kelelahan kerja dapat dipengaruhi oleh bebagai faktor antara lain usia, jenis 
kelamin, penyakit, dan beban kerja. ${ }^{3}$

Beban kerja merupakan suatu pekerjaan yang dibebankan kepada seseorang dan termasuk salah satu faktor penunjang terjadinya kelelahan kerja. Beban kerja yang diterima baik beban kerja fisik maupun mental harus sesuai dengan kemampuan fisik dan mental pekerja. Faktor yang memengaruhi beban kerja yaitu faktor internal dan faktor eksternal. Faktor internal yang dimaksud berasal dari dalam diri seseorang, dan faktor eksternal seperti lingkungan kerja ataupun pekerjaan itu sendiri. Setiap pekerja dapat bekerja secara sehat tanpa membahayakan dirinya sendiri maupun masyarakat sekelilingnya; untuk itu perlu dilakukan upaya penyerasian antara kapasitas kerja, beban kerja dan lingkungan kerja sehingga dapat diperoleh produktivitas kerja yang optimal. ${ }^{4}$

Hasil penelitian yang dilakukan oleh Suoth $^{5}$ terhadap pekerja di PT Nichindo Manado Suisan mendapatkan adanya hubungan antara beban kerja fisik dengan kelelahan kerja yang disebabkan karena pekerja yang berada di bagian mengeluarkan tulang ikan bekerja dengan posisi berdiri. Jadi bila ikan yang harus di slice jumlahnya banyak maka para pekerja tersebut akan berada dalam posisi berdiri untuk jangka waktu yang lama. Demikian pula dengan pekerja di bagian pengemasan yang bekerja dengan posisi duduk; bila pasokan ikan yang harus dikemas berjumlah banyak, maka pekerja tersebut akan berada dalam posisi yang sama untuk jangka waktu yang lama.

Berdasarkan latar belakang ini maka penulis tertarik untuk mengetahui hubungan antara beban kerja fisik dengan kelelahan kerja pada pekerja industri pembuatan mebel kayu di Desa Leilem Satu.

\section{METODE PENELITIAN}

Penelitian ini dilaksanakan di industri pembuatan mebel kayu di Desa Leilem Satu pada bulan Agustus sampai bulan November 2019. Jenis penelitian yang digunakan ialah analitik observasional dengan desain potong lintang. Populasi yang digunakan ialah seluruh pekerja pembuatan mebel di 20 industri pembuatan mebel kayu di Desa Leilem Satu, dengan jumlah keseluruhan pekerja yaitu 72 orang. Jumlah sampel diperoleh menggunakan rumus Slovin dan didapatkan 42 orang. Instrumen yang digunakan ialah stopwatch, timbangan berat badan, Standar Nasional Indonesia (SNI) 7269:2009, dan reaction timer.

Analisis data penelitian ini menggunakan analisis univariat untuk menganalisis setiap variabel penelitian, dan analisis bivariat untuk mengetahui hubungan antara beban kerja fisik dan kelelahan kerja dengan uji korelasi Spearman Rank.

\section{HASIL PENELITIAN}

Pada penelitian ini terdapat 42 responden; semuanya (100\%) berjenis kelamin laki-laki. Tabel 1 memperlihatkan bahwa kelompok usia terbanyak ialah 41-50 tahun dengan jumlah 21 responden (50,0\%), diikuti oleh kelompok usia $>50$ tahun dengan jumlah 14 responden (33,3\%) dan kelompok usia 30-40 tahun dengan jumlah 7 responden (16,7\%). Responden terbanyak dengan masa kerja $>10$ tahun berjumlah 26 orang (61,9\%), diikuti masa kerja $>5-10$ tahun dengan jumlah 14 orang (33,3\%), masa kerja $>1-5$ tahun dengan jumlah 2 orang (4,8\%). Responden dengan kelompok pendidikan SMA berjumlah 17 orang (40,5\%), diikuti oleh kelompok ujian SMP dengan jumlah 12 orang (28,6\%), dan kelompok pendidikan SMP dengan jumlah 12 orang $(28,6 \%)$.

Tabel 2 memaparkan bahwa responden dengan tingkat beban kerja ringan sebanyak 12 orang (28,6\%), tingkat beban kerja sedang sebanyak 24 orang $(57,1 \%)$, dan tingkat beban kerja berat sebanyak 6 orang (14,3\%). Dalam tabel 2 juga ditampilkan bahwa reponden dengan tingkat kelelahan kerja normal sebanyak 2 orang (4,8\%), tingkat kelelahan kerja ringan sebanyak 8 orang (19,0\%), tingkat kelelahan sedang sebanyak 22 orang $(52,4 \%)$ dan tingkat kelelahan berat sebanyak 10 (23,8\%).

Tabel 3 menampilkan hasil uji bivariat dengan menggunakan uji Spearman Rank pada pekerja industri pembuatan mebel 
kayu di Desa Leilem Satu yang dengan kelelahan kerja pada responden memperoleh nilai $\mathrm{p}=0,039$ dan nilai $\mathrm{r}=0,320$. Hal ini menunjukkan bahwa dengan kategori interval korelasi rendah terdapat hubungan antara beban kerja dan arah hubungan positif.

Tabel 1. Distribusi karakteristik responden berdasarkan jenis kelamin, usia, masa kerja, dan pendidikan

\begin{tabular}{ccc}
\hline $\begin{array}{c}\text { Usia, masa kerja, dan } \\
\text { pendidikan }\end{array}$ & $\mathbf{n}$ & $\mathbf{\%}$ \\
\hline Usia 30 tahun - 40 tahun & 7 & 16,7 \\
41 tahun - 50 tahun & 21 & 50,0 \\
$\quad$ > 50 tahun & 14 & 33,3 \\
$\quad$ Total & 42 & 100,0 \\
Masa Kerja & & \\
> 1 Tahun - 5 tahun & 2 & 4,8 \\
> 5 tahun - 10 Tahun & 14 & 33,3 \\
$\quad$ > 10 Tahun & 26 & 61,9 \\
$\quad$ Total & 42 & 100,0 \\
Pendidikan & & \\
SD & 13 & 31,0 \\
SMP & 12 & 28,6 \\
SMA & 17 & 40,5 \\
Total & 42 & 100,0 \\
\hline
\end{tabular}

Tabel 2. Beban kerja dan kelelahan kerja

\begin{tabular}{lcc}
\hline $\begin{array}{c}\text { Beban kerja dan } \\
\text { kelelahan kerja }\end{array}$ & n & \% \\
\hline Beban kerja & 12 & 28,6 \\
$\quad$ Ringan & 24 & 57,1 \\
Sedang & 6 & 14,3 \\
Berat & 42 & 100,0 \\
$\quad$ Total & & \\
Kelelahan Kerja & & \\
$\quad$ Normal & 2 & 4,8 \\
$\quad$ Ringan & 8 & 19,0 \\
$\quad$ Sedang & 22 & 52,4 \\
$\quad$ Berat & 10 & 23,8 \\
Total & 42 & 100,0 \\
\hline
\end{tabular}

Tabel 3. Hubungan antara beban kerja fisik dengan kelelahan kerja pada pekerja industri pembuatan mebel kayu di Desa Leilem Satu

\begin{tabular}{|c|c|c|c|c|c|c|c|c|c|c|c|}
\hline \multirow{3}{*}{$\begin{array}{c}\text { Beban } \\
\text { kerja }\end{array}$} & \multicolumn{8}{|c|}{ Kelelahan kerja } & \multirow[t]{3}{*}{$\mathbf{n}$} & \multirow[t]{3}{*}{$\%$} & \multirow[t]{3}{*}{ Nilai $p$} \\
\hline & \multicolumn{2}{|c|}{ Normal } & \multicolumn{2}{|c|}{ Ringan } & \multicolumn{2}{|c|}{ Sedang } & \multicolumn{2}{|c|}{ Berat } & & & \\
\hline & $\mathrm{n}$ & $\%$ & $\mathrm{~N}$ & $\%$ & $\mathrm{~N}$ & $\%$ & $\mathrm{n}$ & $\%$ & & & \\
\hline Ringan & 1 & 2,4 & 3 & 7,1 & 7 & 16,7 & 1 & 2,4 & 12 & 28,6 & \\
\hline Sedang & 1 & 2,4 & 5 & 11,9 & 12 & 28,6 & 6 & 14,3 & 24 & 57,1 & \\
\hline Berat & 0 & 0,0 & 0 & 0,0 & 3 & 7,1 & 3 & 7,1 & 6 & 14,3 & 0,039 \\
\hline Jumlah & 2 & 4,8 & 8 & 19,0 & 22 & 52,4 & 10 & 23,8 & 42 & 100 & \\
\hline
\end{tabular}




\section{BAHASAN}

Hasil penelitian ini mendapatkan bahwa pada 42 responden penelitian tingkat beban kerja sedang yang terbanyak (57,1\%), diikuti tingkat beban kerja ringan $(28,6 \%)$ dan tingkat beban kerja berat (14,3\%) (Tabel 2). Kategori beban kerja ringan pada responden ialah mengukur, melem HTL, mengecat hasil produksi dalam keadaan duduk, dan memotong kayu dengan menggunakan mesin. Untuk kategori beban kerja sedang, pekerjaan yang dilakukan oleh responden yaitu berupa bor kayu dengan alat, membuat profil pada kayu dengan menggunakan mesin router, dan skap kayu dengan menggunakan mesin gurindam. Untuk beban kerja berat yaitu pekerjaan yang dilakukan secara manual dan dilakukan dengan jangka waktu yang lama, Pekerjaannya berupa memaku kayu, skap kayu secara manual, serta memotong kayu dengan menggunakan gergaji.

Hasil penelitian mendapatkan bahwa reponden dengan tingkat kelelahan kerja normal sebanyak 2 orang (4,8\%), tingkat kelelahan kerja ringan sebanyak 8 orang $(19,0 \%)$, tingkat kelelahan sedang sebanyak 22 orang $(52,4 \%)$ dan tingkat kelelahan berat sebanyak 10 (23,8\%) (Tabel 2). Kelelahan yang dialami oleh pekerja industri pembuatan mebel kayu merupakan akibat dari pekerjaan yang dilakukan secara manual, bekerja lebih dari 8 jam atau bekerja lembur, pemberian pekerjaan yang tidak sesuai dengan keahlian, waktu istirahat yang masih dipergunakan untuk bekerja, serta sumber daya manusia yang kurang sehingga membuat menumpuknya pekerjaan.

Berdasarkan hasil uji bivariat dengan menggunakan uji Spearman Rank pada pekerja industri pembuatan mebel kayu di Desa Leilem Satu didapatkan nilai $\mathrm{p}=0,039$ dan nilai $r=0,320$. Hal ini menunjukkan bahwa terdapat hubungan bermakna antara beban kerja dengan kelelahan kerja pada responden dengan kategori interval korelasi rendah dan arah hubungan positif. Dari hasil penelitian didapatkan bahwa terdapat responden dengan beban kerja ringan namun hasil pengukuran kelelahan kerja- nya yaitu kelelahan kerja berat. Hal ini dapat disebabkan karena pada saat pengukuran faktor usia responden sudah lebih dari 50 tahun sehingga reaksi responden terhadap suatu rangsangan mulai melambat. Selain itu terdapat responden dengan pengalaman kerja yang masih kurang sehingga responden tersebut belum terbiasa dengan tingkat pembebanan yang diberikan. Dalam penelitian ini juga didapatkan responden dengan beban kerja berat namun untuk hasil pengukuran kelelahan kerjanya yaitu kelelahan kerja sedang. Hal ini dapat disebabkan karena responden tersebut telah menguasai pekerjaannya dan sudah terbiasa dengan tingkat pembebanan kerja yang diberikan; responden tersebut telah bekerja lebih dari 10 tahun sehingga telah memiliki banyak pengalaman kerja di bidangnya.

Hasil penelitian ini sejalan dengan penelitian yang dilakukan oleh Pajow et al ${ }^{6}$ terhadap tenaga kerja di PT Timur Laut Jaya Manado yang mendapatkan adanya hubungan antara beban kerja dengan kelelahan kerja yang juga dianalisis dengan uji Spearman $(\mathrm{p}=0,026)$.

Hasil penelitian ini tidak sejalan dengan penelitian yang dilakukan oleh Purba $^{7}$ terhadap perawat di Rumah Sakit Vita Insani Permatang Siantar tahun 2018. Hasil penelitian tersebut menyatakan bahwa tidak terdapat hubungan antara beban kerja dengan kelelahan kerja pada perawat di rumah sakit tersebut $(p=0,634)$.

\section{SIMPULAN}

Berdasarkan hasil penelitian ini dapat disimpulkan bahwa terdapat hubungan antara beban kerja dengan kelelahan kerja pada pekerja industri pembuatan mebel kayu di Desa Leilem Satu.

Bagi pengelola industri, perlu adanya penyesuaian antara pekerjaan yang diberikan kepada pekerja yang bekerja kurang dari 1 tahun karena para pekerja tersebut masih dalam tahap penyesuaian terhadap pekerjaan dan proses belajar sehingga pekerjaan yang diberikan kepadanya harus berbeda dengan pekerja yang telah bekerja lebih dari 1 tahun. Bagi para pekerja, harus 
memperhatihan jam kerja yaitu 8 jam dan juga memperhatikan jam istirahat yang harus dipergunakan untuk istirahat dan bukan untuk bekerja. Perlu adanya penelitian lebih mendalam terkait dengan faktor-faktor yang memengaruhi kelelahan kerja seperti jam kerja pada pekerja industri pembuatan mebel kayu didesa Leilem Satu.

\section{DAFTAR PUSTAKA}

1. Kementerian Kesehatan Republik Indonesia. INFODATIN. Pusat Data dan Informasi Kementerian Kesehatan RI. Hipertensi. Jakarta: Kemenkes RI., 2014.

2. Undang-Undang Republik Indonesia Nomor 13 Tahun 2003 tentang Ketenagakerjaan.

3. Suma'mur PK. Hygiene Perusahaan dan Kesehatan Kerja. Jakarta: Sagung Seto,
2009.

4. Undang-Undang Republik Indonesia Nomor 36 tahun 2009 tentang Kesehatan.

5. Suoth L. Hubungan antara umur, status gizi dan beban kerja fisik dengan kejadian kelalahan kerja pada pekerja di PT. Nichindo Manado Suisan. Kesmas. 2017;6(2).

6. Pajow DA, Sondakh RC, Lampus BS. Hubungan antara Beban Kerja dengan Kelelahan Kerja pada Tenaga Kerja di PT. Timur Laur Jaya Manado. Pharmacon. 2016;5(2):144-50.

7. Purba SIA. Hubungan beban kerja dengan kelelahan kerja pada perawat di Rumah Sakit Vita Insani Pematangsiantar Tahun 2018. Available from: http://repositori.usu.ac.id/handle/1234 56789/6100. 